\title{
Research on Packaging Design and Modern Business Development
}

\author{
Chengrui Duan ${ }^{1}$ and Xiaodan $\mathrm{Li}^{2}$ \\ ${ }^{1}$ Shenyang Aerospace University, Shenyang \\ ${ }^{2}$ Shenyang University, Shenyang
}

Keywords: Packaging design; Environmental protection; Future business development

\begin{abstract}
As business and economy develop, packaging design is being improved and innovated constantly. The future packaging design should adapt to business development and environmental protective living surroundings. So the future packaging design needs to be discussed and planned deeply.
\end{abstract}

\section{Introduction}

Packaging design has a long history of several hundred years since European Industrial Revolution. It plays an important role in our life. It can present various states. There are mainly two aspects of content about packaging design. The first one is three-dimensional design. Three-dimension design mainly solves the aesthetic relation between structure and shape. Three-dimension design is also used to deal with rationality of this relation within the design and production process, similar to protect goods. The basic functions of packaging design are convenient transportation, storage function and special needs of different product categories. The second one is visual communication design. The visual communication design plays a main function in giving the appearance of a 3D shape and doing decorative pattern of flat packaging. The visual communication design has the ability of promoting product visually and increasing additional value, so that it can bring merchants more benefit.

In the circulation of goods, there is an important role of packaging design, which needs to attract consumers' attention and stimulate consumers' purchasing desire. The packaging design is knowledge that can stimulate consumers to purchase and study psychology and action. How to attract consumers' attention? How to draw their interest deeply? How to stimulate consumers to purchase? There are many aspects of packaging design that can complete packaging effects on consumers[1].

\section{The Effect of Packaging Designs on Consumer Psychology}

Mr. Landau, the American master of industrial design, thinks that A good designer must be a shrewd psychologist.

The design ideas of packaging should be regarding consumers as a center and try every means to stimulate and satisfy consumers' psychological need. Japanese merchants have a business sense that goods with big profit are not the best, goods with great satisfaction are the best.

Contribution that made by Bauhaus in $20^{\text {th }}$ century is that he put forward design aims at human beings, not products. The sentence has already been famous several decades ago, but it was not understood fully by most designers. As a result, there is always a dangerous tendency of design ----going his/her own way of design thought and institute. This tendency leads designers to consider little social function and forget the basic point of social existence--- necessity of learning human beings[2].

Design must study people's perception and emotion in the consuming action process. Study on buyers' psychology is to attract consumers' attention. Designers should design images that include rich imagination, creativity, and sensitive beauty. The image aims to arouse the corresponding emotion of consumers. The beauty of packaging form needs to satisfy consumers' eyes and their heart. If only satisfying their heart, people can purchase the goods that they really like. In order to satisfy the psychological demands of today's social choices, packaging design should pay attention 
to consumers' emotion and custom. It means that packaging should adapt to consumers. Information needs to be conveyed between packaging and people by designing language that has been familiar and accepted. If so, emotional communication can be produced. Designing language should be understood by people, especially by common people.

Color Elements. As a visual physiological phenomenon that can arouse people' emotion, color has a general meaning in real life and many subject areas. Packaging design is a creative activity that is accomplished by many methods and techniques, but the value and role of color with proprietary property are irreplaceable. Designers should have an intuitive sense of color aesthetic value and the ability to regard color as visual linguistic expressing techniques during packaging and decorating process because of special psychological effect of color.

Understanding of color physiological role is sometimes abstract and vague, but coloring emotion that it produces can let consumers make different association on packaging. Color, as an independent subject, has natural law and property. Based on natural law and property, emotional factors that color produces are composed of subjective emotions and objective emotions. Subjective emotions are coloring emotion that individual subjective consciousness produces. The age, nationality, education, environment and faith can determine good or bad evaluation of color. The main selling objects of the goods and preferences and taboos of color in selling areas must be taken into consideration. The objective emotions are people's general recognition of visual colors.

In the packaging design, in order to convey a unique property and the value of goods, these are other things that need to be considered: Consumers can directly identify the product property within the package depending on the natural color of goods. For example, orange juice is saffron and coffee is brown. According to color preference of the main selling objects and selling areas, the hue that can convey goods' property and arouse favorable impression should be used so that the hue can contribute to abstract conceptual association. If so, packaging can express the connotation of goods.

Shaping Elements. Packaging design assembles a complete visual shapes that can convey information about goods and guide attention of consumers by colors, shapes, text and decoration. When designers assemble visual shapes by designing elements, they should determine the form of shapes based on whether implied meaning of shapes can express consumers' requirements on ideal value of goods. It means that designers can depend on shapes to strengthen the appeal[3]. When designers choose shapes' techniques of expression, such as specific shapes, abstract symbols or exaggerated drawing, they should consider that whether they can create an inductive effect with psychological association. If shaping design should be persuasive, there are many things that need to be noticed during material selection and concrete performance of shapes: The first one is the clear-cut theme. Any goods have its own unique individual language, so theme positioning must be determined before designing. It could be trademarks, products, consumers or shapes with implied meanings. If so, it is possible to clearly distinguish the natural characteristics of the product from those of the same kind. The second one is explicitness and succinctness. Ways of expression can be selected depending on multi-aspect characteristics of the main selling objects and understanding of shaping language during designing. Complex shapes may influence subject positioning because of limitation of packaging's size. Shapes can be used by doing more with less, so that it is more effective to convey visual information accurately. The third one is the authenticity. There are many techniques in selecting and using shapes but the key point is that there should not be any cheating guide. Shapes with cheating guide maybe accepted by consumers temporarily, but it can not keep consumers purchasing eternally. The fourth one is specificity and individualizing. Goods will have competitiveness as long as goods have specificity. Packaging can arouse consumers' attention as long as it has specificity. As a result, the original language that embodies shapes is favorable guarantee of successful packaging design.

Text Elements. In general, text on the packaging is arranged and selected to explain content of goods quickly except the brand name. There are following rules that need to be obeyed about text fond design during packaging:

There should be different designs according to the relationship of texts. There is an emphasis on sales promotion and consideration of text in selling areas. Expressive ability of visual modeling 
should not be ignored because of identifying features of text. There are difference and utilization of artistic calligraphy and printed word; The distinguishing ability to the aesthetic nature of the text; Obeying the features of the product and attracting consumers' attention. Font design need to be concise and clear and should be good for recognition of consumers. At the same time, arrangement, layout, size and decoration play an important role in font designs.

Modeling Elements. Modeling within packaging design presents diversity because of differences in product. Based on structural components and a range of application, modeling design of packaging must be understood from three different angles, they are producers, sellers and consumers[4]. The aim of modeling design of packaging is mainly to create a kind of special individualizing, stand out goods and convey goods. However, there are always many limitations of techniques within packaging structure, there is consideration that needs to be taken during designing: features of materials, such as production technology, paper restrictions, glass, plasticity of plastics and so on; loading line means that what the loading equipment is like; packaging line means that what the block device is like; label sealing and pasting line means materials and equipment of label sealing and pasting. Market factors also need to be taken into consideration. All in all, structural design of packaging is determined by two aspects, they are material equipment and market.

\section{The Impact of Green Design and Environmental Protection Packaging Design on Market}

According to statistics, $60 \%$ of Germany, $60 \%$ of English and $50 \%$ of Chinese are willing to pay more money for green designing product. It shows that green design is penetrating people's hearts. The development of environmental packaging has become a historical trend of packaging design. The standard of green design is that packaging can be recycled or not. It is reflected in three aspects, they are saving material and energy during packaging production, improving the recoverable rate, regeneration rate and convenient destruction of packaging material, and not destructing environment. Specifically, firstly concurrent design mode can be adopted in design. At the beginning of designing, the whole designing link needs to be considered. Relevant personnel of design should design, communicate together do feedback and amend in time. They need to take recycling and recovery of packaging material as the basic rule. At the same time, they need to consider that how material that can not be recycled is destructive. Secondly, solving packaging pollution should be risen to national behavior depending on the relevant law of packaging design. Last, all the people should be educated and cultivated environmental consciousness. Environmental education and environmental activities should be risen to social behavior.

Decreasing the Variety and Amount of Packaging Material. Packaging structure should be designed reasonably so that maximum reduction can be achieved in packaging product from functioning, consumable and printing. Complex superposition of packaging structure, packaging level and volume should be avoided. Over-packaging and exaggerated packaging appears. The device that is not useful and abstruse will mislead consumers. Material will be wasted, so this action is not worth advocating.

In general, packaging designers try best to use different kinds of material for appearance needs because there are too many packaged parts. The purpose of this kind of packaging design is to attract more and more consumers and improve the grade of the product. There is no doubt that using different kinds of material can achieve a certain effect, but is there a more appropriate way? The really successful packaging design must contain special connotation that other packaging design can not compare with, such as humanized simplicity of packaging, but not losing integrity and specificity, functionality and environmental protection of style. If one kind of parts or one kind of material is enough so personnel should use one kind of that. If so, it will help to recycle the product. For example, a Germany company, called WHIRLPOOL, reduced 20 kinds of packaging material to 4 kinds of packaging material. The cost in dealing with waste was reduced by $50 \%[5]$.

Recognition on Traditional Natural Packaging Material. A long time ago, our ancestor started to use existing material directly to package things that they would use in their labor activities and life. As a result, the special green packaging quality connotation and national packaging style are formed. Their simple natural value and environmental consciousness is kept until now, and will 
never lose luster. Materials of plant blade packing are Bamboo leaves, lotus leaves, reed leaves and so on. For example, the special packaging style in Jinan is lotus leaf bags. The baozi is wrapped directly by natural lotus leaves and steamed. Such baozi will have a unique flavor and packaging material will be reduced by this kind of packaging. The special packaging style in Yunnan is grass fiber packaging. People who are living here grow rice and raise poultry for a long time. Eggs are used to exchange goods, so people use a flexible and firm straw to weave reticular straw bags, which can put the eggs in. Eggs that are wrapped in reticular straw bags are more fresh. It will show people the natural freshness of the original. There is a statement that eggs in Yunnan can be dressed in a rope. The next one is bamboo packaging. Our ancestors made an indissoluble bond with bamboo during labor activities for many years. Bamboo baskets that can be regarded as packaging container are used until now. Bamboo baskets are weaved by high-toughness and strong bamboo cane simply. There are no redundant and complex details on them. On contrary, bamboo baskets give people a special natural feeling. All kinds of foods can be put in. Foods are not easy to get bad because there are many intervals between bamboo canes. The last one is pottery packaging. Pottery was used widely in common life since ancient times. Pottery was made of natural sediment. Pottery is convenient to pack because of its hard quality. Pottery is more convenient to use and recycle to the nature. Nowadays, in the packaging design of Chinese liquor, a better application between pottery and porcelain can be seen everywhere. This kind of packaging is still not losing its modern sense and immersed by Chinese culture because of special design, artistic dealing and combination of tonal and text. The miraculous combination is formed based on environmental packaging. It shows that packaging can save more energy and good for the environment if packaging is artful, suitable for local conditions and based on local materials. In this sense, development potential of such packaging can not be evaluated.

\section{Conclusion}

With the development of times and innovation of new technology and materials, packaging design also develops constantly. At the beginning of packaging design, protecting goods and improving value are more important, but the idea of compound environmental protection will be more integrated with consumption in the future. Packaging design will be an inseparable part of human life. The selection and utilization of packaging designing material will influence our environment and economy. So future packaging design promotes Benign circular development of business by green protective recycle. It will be more beneficial to human beings and society.

\section{References}

[1] Z.Chen: Symbolization of Logo Design [J], Packaging Engineering, 2013, 24(3). (In Chinese)

[2] L.G. Schiffman: Consumer Behavior [M], Shanghai: East China Normal University Press, 2012.

[3] E.P. Yuan: Investigation of Consumption Psychology and Packaging Design [J], Packaging Engineering, 2003, 24(3). (In Chinese)

[4] L.Jin: Nationality of Packaging Color Design [J], Packaging Engineering, 2014, 6(5). (In Chinese)

[5] G.X.Yang: Discussion on Green Packaging Design [J], Packaging Engineering, 2013, 6(5). (In Chinese) 